The results presented bring together some of the previous apparently conflicting data, and clearly support Salzman's contention ${ }^{2}$ that deoxyribonucleic acid and protein content cannot be used indiscriminately as indications of cell number in tissue culture.

This work was supported by a grant from the United States Public Health Service C2928 (C2).

Rolla B. HILI, JUN.

Kraus G. Bensch

STANLEY STMBONIS

Donald W. King

Department of Pathology,

Yale University School of Medicine,

$$
\begin{aligned}
& \text { New Haven, } \\
& \text { Connecticut. } \\
& \text { March } 20 .
\end{aligned}
$$

'Siminovitch, L., Graham, A. F., Lesley, S. M., and Nevill, A., Exp. Cell Res., 12, 299 (1957).

2Salzman, N. P, Biochim. Biophys. Acta, 31, 158 (1959).

${ }^{3}$ King, D. W., Bensch, K. G., and Simbonis, S., Cancer Res., 18, 382 (1958).

\& Lajtha, L. C., Oliver, R., and Ellis, F., Brit. J. Cancer, 8, 367 (1954).

"Ceriotti, G., J. Biol. Chem., 198, 297 (1952).

${ }^{6}$ Ogawa, V. I., and Eagle, H., Proc. Soc. Exp. Biol. and Med., 91, 305 (1956).

\section{Stress Activation of Adrenal Glomerulosa}

THE experimental data concerning the hormonal regulation of adrenal glomerulosa and its mineralocorticoid production ${ }^{1}$ are still inconclusive. 'The demonstrated dependence of the glomerulosa reaction on the presence of pituitary ${ }^{2}$ as well as on adrenocorticotrophic hormone ${ }^{3}$ is contradictory to the absence of increased aldosterone secretion by adrenals perfused with either adrenocorticotrophic or somatistrophic hormone in vitro ${ }^{4}$. Nevertheless, it can be assumed that the former, and stress, activate the adrenal glomerulosa indirectly ${ }^{5}$, mediated by the pituitarydependent glucocorticoid produetion, which becomes properly balanced by means of mineralocorticoids ${ }^{6}$. This view will be supplemented by further experimental results.

Adult Wistar rats, males or females, divided into three separate groups (96 animals altogether), were subjected to stress by a single intra-muscular injection of $0.3 \mathrm{ml}$. 4 per cent formaldehyde/100 gm. bodyweight. At intervals of $3,6,12,24$, and $48 \mathrm{hr}$. rats were killed. Frozen sections of adrenals were stained with sudan black $B$ and with oil red $O$ on lipids. The width of the zona glomerulosa was measured at a magnification of $\times 330$, in all four quarters of the adrenal cortex. The number of leucocytes, eosinophils, and the differential count of leucocytes were also determined; the spleen and thymus were examined histologically.

In the unstressed rats of all three series the lipid content of the zona fasciculata was relatively low, resembling that of series $B$, described previously ${ }^{5}$. 3-6 hr. after the formaldehyde injection a considerable decrease and even disappearance of lipids took place in the fasciculata. The lipid content of the glomerulosa, however, remained unchanged. 24-48 $\mathrm{hr}$. after the injection the lipids of fasciculata were gradually restored and simultaneously the glomerulosa was activated, as judged from the depletion of their lipids and from a statistically highly significant $(P<0.001)$ enlargement (Fig. 2). The glomerulosa activation was associated with the transformation of light centres of spleen lymphatic nodules, previously

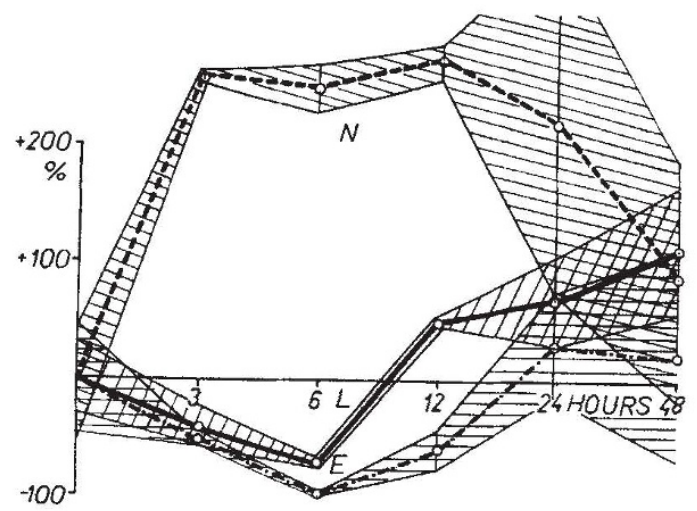

Fig. 1. The stress changes of neutrophils $(N)$, lymphocytes $(L)$ and eosinophils $(E)$ expressed as a percentage of the mean initial value, with their standard deviations

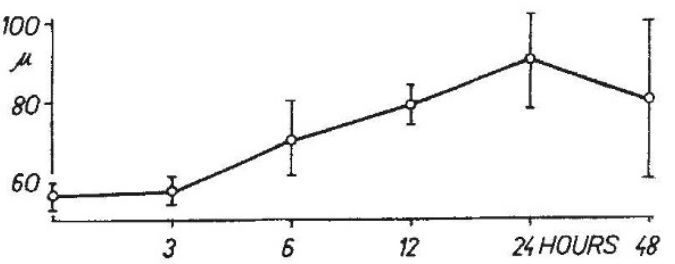

Fig. 2. The stress changes of the mean width of the zona glomerulosa in $\mu$ and their standard deviations

activated by stress, into resting ones, and with the return of neutrophils to the initial level; that of lymphocytes $(P<0.01)$ and eosinophils rose above the initial level (Fig. 1).

The findings show that the activation of the glomerulosa corresponds to changes in the leucocytes and the lymphoid tissue opposite to those found during the glucocorticoid phase of stress. Taking into account the mutual antagonism between mineralocorticoids and glucocorticoids ${ }^{6}$, we may suppose that the activation of the glomerulosa is elicited by the antecedent glucocorticoid effects, especially their influence on electrolyte and water exchanges through the cell wall. Hence the stress reaction of the glomerulosa occurs as a balance to the glucocorticoid effects by abolishing them. The stress period can thus be divided into well-definod glucocorticoid and mineralocorticoid phases.

\section{HILL \\ K. Dvơ̌ÁK}

M. PospíšriL

Institute of Biophysies,

Czechoslovak Academy of Sciences, Brno.

Department of Histology and Embryology,

Faculty of Medicine,

University of Brno,

Czechoslovakia.

March 9.

${ }^{1}$ Giroud, C. J. P., Stachenko, J., and Venning, E. H., Proc. Soc. Exp. Biol. Med., 92, 154 (1956). Eisenstein, A. B., and Hartroft, P. M., Endocrinol., 60, 634 (1957)
stein, A. B., ibid., 60, 641 (1957).

${ }^{2}$ Kovács, K., Kovács, B. M., Kovács, G. S., and Petri, G., Naturwiss., 44, 241 (1957). Nagy, A., Olah, A., and Karady, S., Nature, 180, 1481 (1957).

${ }^{3}$ Wexler, B. C., Rinfret, A. P., Griffin, A. C., and Richardson, H. L., Endocrinol., 56, 120 (1955). Lever, J. D., ibid., 58, 163 (1956).

${ }^{4}$ Rosenfeld, G., Rosemberg, E., Ungar, F., and Dorfman, R. I. Endocrinol., 58, 255 (1956).

${ }^{5}$ Hill, M., Pospłšll, M., and Dvor̆ák, K., Experientia, 14, 419 (1958). 'Selye, H., Science, 121, 368 (1955); Experientia, 11, 35 (1955). 